\title{
Efficacy of lysine versus mupirocin in the treatment of non-diabetic foot ulcer: the sessing scale for assessment of pressure ulcer
}

\author{
Sridhar Prasad Y. P. ${ }^{1}$, Sandeep B. ${ }^{1 *}$, Shashi Kumara ${ }^{1}$, Prathima C. ${ }^{2}$, Vani J. $^{3}$
}

\begin{abstract}
${ }^{1}$ Department of Pharmacology, Chamarajanagar Institute of Medical sciences, Chamarajanagar, Karnataka, India ${ }^{2}$ Department of Pharmacology, JSS Medical College, JSS Academy of Higher Education and Research, Mysore, Karnataka, India

${ }^{3}$ Department of Pharmacology, Akash Institute of Medical Sciences and Research, Bengaluru, Karnataka, India
\end{abstract}

Received: 23 November 2020

Revised: 06 December 2020

Accepted: 08 December 2020

*Correspondence:

Dr. Sandeep B.,

Email: sandeepcims18@gmail.com

Copyright: (c) the author(s), publisher and licensee Medip Academy. This is an open-access article distributed under the terms of the Creative Commons Attribution Non-Commercial License, which permits unrestricted non-commercial use, distribution, and reproduction in any medium, provided the original work is properly cited.

\begin{abstract}
Background: This present studies intended to evaluate the wound healing ability, efficacy and tolerability of lysine cream $(15 \%)$ in non- diabetic foot ulcer assessed by way of sessing scale.

Methods: A randomized, open-label, interventional study was directed on 20 subjects (participants) non-diabetic ulcers. Participants were grouped into two groups, control $(n=10)$ and case $(n=10)$. The control was treated with standard treatment with mupirocin and the test group was treated with standard treatment alongside lysine cream (15\%) twice every day. Wound healing in the participants was assessed by the sessing scales.

Results: A total of 20 participants were allotted into two groups. The results expressed as mean \pm standard deviation values imply the size and depth of the foot ulcer from the first week to the 8th week. Both the groups showed a significant increase the ulcer healing and decrease the pressure of foot ulcer of over a period of 8 weeks. Assessment of the first week showed no significant ulcer healing and its pressure. The overall outcome indicated that the lysinetreated group extensively reduced each of the parameters favouring wound healing than the standard therapy with mupirocin (control group).

Conclusions: Results concluded that, lysine cream is better efficacious in the repair of wound and additionally well tolerated compared to mupirocin.
\end{abstract}

Keywords: Sessing scale, Non-diabetic foot ulcer, Lysine, Mupirocin

\section{INTRODUCTION}

Wound healing is an effective process that ideally activates the reclamation of tissue integrity and capacity. It is the response of a living being to damage which brings approximately fixation or reconstitution of a deformity in an organ or tissue. ${ }^{1}$ Healing pathways are set into motion without delay from the time of infliction of damage. Tissue response to a bodily injury occurs in special ways: scar development - fixing of a deformity with a trade cellular grid, or tissue regeneration - whole pastime of the authentic tissue structure. ${ }^{2}$ The various processes occurring during wound healing can be organised into three broad phases: inflammation, proliferation, and remodeling. ${ }^{3}$ These overlapping phases act in a highly coordinated manner to restore the tissue integrity and function.

The various strategies in during wound recovery can be prepared into three extensive stages: irritation, proliferation, and reworking. ${ }^{3}$ These overlapping stages act in a quite coordinated manner to repair the tissue integrity and feature. ${ }^{4}$ 
The soluble components that provoke infection are cytokines, affluent elements, proteases, eicosanoids, kinins, and mobile metabolites. These elements begin a development of features that enterprise to settle the injury, take away attacking creatures, to return the damage to preinjury country. The potential of the injury restoration components to accomplish these goals to an amazing quantity is based upon the management of inflammatory mediators.

Growth factors, which shape the base of the modern-day have a look at, are the engines, or modulating factors, that force wound healing. They are a vital class of tissue repair signalling peptides upregulated all through the inflammatory segment which target non-hematopoietic cells. $^{5}$ The improvement factors that anticipate basic features and work domestically in wound healing are platelet-derived growth issue (PDGF), epidermal increase issue (EGF), fibroblast boom factor (FGF), insulin-like increase factor (IGF), keratinocyte boom issue (KGF), transforming growth thing- $\beta$ (TGF- $\beta$ ) and vascular endothelial increase aspect (VEGF). ${ }^{6,7}$

Wound healing is a dynamic procedure that optimally results in recuperation of tissue integrity and function. ${ }^{5}$ It represents the reaction of an organism to damage which ends up in restore or reconstitution of an illness in an organ. ${ }^{6}$ In case of some unique state of affairs like patients having ulceration associated with other comorbidities such as peripheral vascular sickness and others which do now not promote the healing techniques due to the absence of pedal pulsations. Amino acids play a supportive function to hasten recuperation approaches in ulcer related to others comorbidities. Glycyl-L-histidyl-L-lysine (GHK) copper complex is a human tripeptide present in the plasma. Various studies in the examination labs have shown that human tripeptide GHK-Cu has plenty of activities which include, anti-inflammatory, anti-oxidant, initiation of wound healing and regeneration, incitement of collagen and glycosaminoglycan blend in dermal fibroblasts, and development of blood vessels. ${ }^{8}$

L-lysine alone also has shown to produce remarkable improvement in both the rate and the quality of wound healing. On histopathological examination, lysine treated wounds of rodents have showed a thickening of dermoepidermal layer, with increased but controlled cell proliferation. The molecule gives qualitatively better and much quicker healing with less scar and deformation in a clean cut model. It is postulated that, lysine, by acting as a cell surface bridge favours angiogenesis by binding the growth factors to their receptors. ${ }^{9}$

\section{METHODS}

\section{Study design}

A randomized, open-label, interventional, comparative, prospective parallel-group study was carried out on the patients with non-diabetic foot ulcers attending the outpatient department of medicine in Madras medical college and Government general hospital, Chennai, Tamil Nadu, between April 2009-November 2009. The study duration of each patients was 8 weeks with 8 visits. The study length for each patient was eight weeks with 8 visits. The study was conducted after obtaining approval from the institutional ethical committee.

The study was conducted in the outpatient clinic, and department of diabetology, Madras medical college and Government general hospital, Chennai. Out of 56 screened, 20 patients without diabetic ulcer were recruited for the study.

\section{Inclusion criteria}

The study included patients of age 30-70 years of both the genders and patients with foot ulcer.

\section{Exclusion criteria}

The study excluded patients with diabetes, patients diagnosed to have vascular occlusion, pregnant and/or breast feeding mothers, patients not willing to give informed consent, and wound swab positive for pathogenic bacteria.

\section{Ethical consideration}

The study was started after acquiring approval from the institutional ethical committee. Patients' non-diabetic ulcer attending the medicine department, Madras medical college and Government general hospital, Chennai, who were already on standard treatment for the non-diabetic ulcer, were explained about the purpose of the study, study procedure, and possible side effects in vernacular language. Written informed consent was obtained from individuals willing to participate in the study in the prescribed format in regional language. The left thumb impression was received from the illiterate patients in the presence of impartial witness.

\section{Treatment schedule}

Twenty subjects were screened and divided into two groups namely, control and test. Each group with allotted 10 participants was followed by drug treatment and management over a period of 8 weeks.

\section{Control}

Routine ulcer care $(n=10)$ was done with standard therapy (mupirocin 2\%) and dressing was done with non-adherent absorbent gauze.

\section{Case}

Routine ulcer care $(n=10)$ was done with standard therapy using lysine $15 \%$ cream and dressing was done with nonadherent absorbent gauze. 


\section{Evaluation and assessment tool}

Assessment of improvement in the patient's wound condition

Sessing scale is utilized for assessing pressure ulcers. This appraisal strategy depended on a seven-point arrangement of meeting boundaries including presence of granulation tissue, contamination, seepage, rot and eschar as assessed by the clinical experts. Every boundary is scored out on an estimation from 0 to 6 , with 0 demonstrating ordinary skin in danger for an injury and 6 showing breaks in the skin with the presence of disease, seepage, putrefaction, and conceivable sepsis. Positive scores indicated wound recuperation; negative scores indicated intensifying of the injury.

\section{Statistical analysis}

Descriptive statistical analysis was conducted by the statistical package for the social sciences (SPSS) software version 16. Individual visit data were entered in excel sheet. Mean \pm standard deviation (SD) was considered to be statistically significant at $\mathrm{p}<0.05$. The results were denoted by tabulation and graphical representation.

\section{RESULTS}

The 20 participants were allocated into two groups. Control treated (mupirocin 2\%) with standard treatment $(n=10)$. The test group received standard treatment followed by lysine $15 \%$ cream. Sessing score interpretation (*scale score $=$ previous stage-current stage) revealed significantly improve the ulcer healing in case (visit 2, visit 9 and score followed by $2.35,1.20$ and 1.27 ) than control (visit 2, 9 and score followed by $2.05,1.5$ and 1.00) (Table 1). In addition, the mean \pm SD values indicate of ulcer healing significantly improve the ulcer healing in case 59\% (p<0.001) and control groups $41 \%(\mathrm{p}<0.650)$ (Table 2$)$. In addditon, topical application of lysine in the case group over a period of 8 weeks twice daily significantly reduced the size and depth of the ulcer when compare to baseline data.

\section{Scale score $=$ previous stage-current stage}

Sessing score of both the study groups was calculated. Sessing score interpretation showed significant improvement in the healing of the ulcer in group A. In the group B, there was an improvement in the sessing score, but it was less than that of group A.

Table 1: Sessing scale.

\begin{tabular}{|lll|}
\hline Sessing scale & Case (A) & Control (B) \\
\hline Visit 2 & 2.35 & 2.05 \\
\hline Visit 9 & 1.20 & 1.5 \\
\hline Score & 1.275 & 1.00 \\
\hline
\end{tabular}

Each row and column represents mean \pm SD of rate of healing/percentage, measured at every visit by sessing scale. The differences in mean $\pm \mathrm{SD}$ show significant increase the rate of ulcer healing with lysine-treated group than control group. $\mathrm{P}<0.05$ was considered to be statistically significant as derived from descriptive method followed by two-tailed student's t-test.

The results depicted in Figure 1 indicate mean values of ulcer size during each visit from the 1st to 8th week in control versus case groups. There was a significant reduction of size of the ulcer the case groups when compared to the control group with standard treatment alone.

Table 2: Rate of healing (\%).

\begin{tabular}{|c|c|c|c|c|c|c|}
\hline \multirow{3}{*}{ Groups } & \multicolumn{2}{|c|}{ Size of the ulcer } & \multicolumn{2}{|c|}{ Size of the ulcer } & \multirow{3}{*}{ Rate of healing (\%) } & \multirow{3}{*}{$P$ value } \\
\hline & \multicolumn{2}{|c|}{ Base line visit } & \multicolumn{2}{|c|}{ Last visit } & & \\
\hline & Mean & $\%$ & Mean & $\%$ & & \\
\hline $\mathbf{A}$ & 2.85 & 100 & 1.00 & 38 & 59 & $<0.001$ \\
\hline B & 2.70 & 100 & 1.90 & 69 & 41 & $<0.007$ \\
\hline$P$ value & 0.650 & & $<0.001$ & & & \\
\hline
\end{tabular}

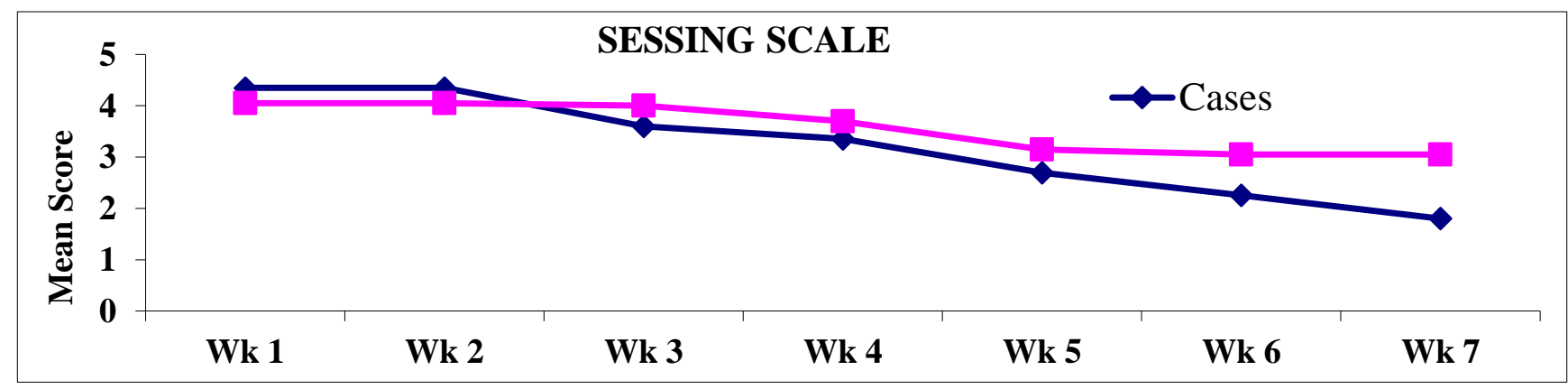

Figure 1: The relationship between wound changes and ulcer pressure is observed by the sessing scale compared with diameter. 


\section{DISCUSSION}

The aim of the study is to assessment of efficacy of lysine versus mupirocin in the treatment of non-diabetic foot ulcer. The parameters inclusive of age distribution, body mass index and distribution of sex have been taken into consideration and was analyzed for any statistical significance. When age distribution were analyzed among the study groups, it has been found out that the suggest age distribution some of the examine groups had been 54.75 and 53.80. There turned into no statistical significance among study groups $(\mathrm{p}=0.720)$. In group A, 6 participants had been male and 4 patients had been female. For group B, 5 male and 5 female participants have been recruited. Statistical analysis confirmed no statistically significant ( $p=0.752)$. This shows that both the groups were matched for gender. The mean body mass index among the study groups were 26.26 and 26.40 in group A and B respectively. Data became analyzed and observed that there's no statistically significant among the study groups $(\mathrm{p}=0.833)$.

The higher the sessing scale score, better is the status of the pressure ulcer. This scoring also favoured group A (score1.275). In fact, both the groups (group A score-1.275 versus group B-1.00) (Table 1) showed improvement at the end of the study. But in group A, the improvement was very obvious as proven by the score values and also the study subjects had a sense of wellbeing. Rate of healing was $59 \%$ in group A and $41 \%$ in group B. Statistical analysis at the end of the study showed significant difference between the groups $(p<0.001)$. This suggests that lysine cream is effective in the healing of ulcer when compare to mupirocin treated group (Figure 1).

The role of immunonutrition such as lysine in wound healing has been a place of both interest and controversy for many years. The poor or malnourished patients have expanded period of wound recovery or impaired healing. Immune-modulating organic vitamins were constantly harvested for wound repair. ${ }^{10}$ Review literature of these immune modulating nutrients elucidated their roles in wound healing via preventing the infections and thereby improving the immune device. However, our take a look at topically handled with lysine proven better wound recovery belongings thru upregulate the wound restore mechanism through modulating the wound organic surroundings. Topically, lysine is a wound recuperation peptide which was replaced through its $\mathrm{D}$ enantiomers, yielding an analog is prevent the bacterial increase and considerably hasten the wound healing activity. ${ }^{11}$

Hypothesis suggest that in during immunocompromised and malnourished patients, there may be a scope to speed up the wound healing activity; therefore, a large number of molecules are being tested for the promotion of therapeutic angiogenesis consisting of vascular endothelial boom element L-lysine monohydrochloride (L-lysine) which has been shown to promote copper complicated of a GHK peptide and acetylserine system. On the opposite hand, lysine has the ability for closure of the wound by way of notably greater lysine acetylation in activated keratinocytes. ${ }^{12,13}$

No adverse effects had been suggested at some stage in the examine period which indicates that topical lysine became well tolerated. The biochemical parameters along with blood sugar, urea, serum creatinine, and electrolytes which had been executed to indicate that topical lysine was nicely tolerated.

\section{Limitations}

The study was done in small number of patients and the prevalence of non-diabetic foot ulcer is minimal when compare to diabetic foot ulcer.

\section{CONCLUSION}

Results concluded that, lysine cream is better efficacious in the repair of wound and additionally well tolerated compared to mupirocin. Among all subjects who had taken treatment for non-diabetic foot ulcer with lysine cream for 8 weeks together with well-known remedy showed reduction inside the dimensions and depth of the ulcer and there was hastening of the wound healing activity.

\section{ACKNOWLEDGEMENTS}

Authors acknowledge the help of the institution for the smooth conduction of this study.

Funding: No funding sources

Conflict of interest: None declared

Ethical approval: The study was approved by the Institutional Ethics Committee

\section{REFERENCES}

1. Henry G, Garner WL. Inflammatory mediators in wound healing. Surg Clin North Am. 2003;83(3):483507.

2. Thorne CH, Beasley RW, Aston SJ, Bartlett SP, Gurtner GC. Grabb \& Smith's Plastic surgery, 6th edition. Chapter 2: Wound healing. Lippincott Williams \& Wilkins. 2006;322-44.

3. Australian Wound Management Association. Standards for wound management. Australian Wound Management Association. 2002. Available at: http://www.awma.com.au/ publications/2007/awma_standards.pdf. Accessed on: 25 April 2020.

4. Breasted JH. The Edwin Smith Surgical papyrus. Chicago: University Chicago press. Oriental Institute Publications (OIP). 1991;1:1930.

5. Cromack DT, Sporn MB, Roberts AB. Transforming growth factor beta levels in rat wound chambers. J Surg Res. 1987;42:622-8.

6. Steed DL. The role of growth factors in wound healing. Surg Clin N Am. 1997;77:575-86. 
7. Vilcek J. The cytokine handbook. 3rd edition. San Diego. Academic press. 2003;1998.

8. Lorenz HP, Longaker MT. Mathes Plastic surgery-6. Trunk and Lower extremity. 2nd edition. Saunder's Publication. 2003;219.

9. Gupta RN, Pandey A, Ghosh S. Diabetic foot: Pathogenesis, management and recent advances. Pharma Times. 2000;40:123-45.

10. Novak TE, Babcock TA, Jho DH, Helton WS, Espat NJ. NF-kappa B inhibition by omega-3 fatty acids modulates LPSstimulated macrophage TNF-alpha transcription. Am J Physiol Lung Cell Mol Physiol. 2003;284:84-9.

11. Chow O, Barbul A. Immunonutrition: Role in wound healing and tissue regeneration. Critical reviews. Wound healing society. Adv Wound Care. 2012;3:4953.
12. Ramsey SD, Newton K, Blough D, McCulloch DK, Sandhu N, Reiber GE, Wagner EH. Incidence, outcomes, and cost of foot ulcers in patients with diabetes. Diabetes Care. 1999;22(3):382-7.

13. Chow O, Barbul A. Immunonutrition: Role in wound healing and tissue regeneration. Critical reviews. Wound healing society. Adv Wound Care. 2012;3:4953.

Cite this article as: Sridhar PYP, Sandeep B, Kumara S, Prathima C, Vani J. Efficacy of lysine versus mupirocin in the treatment of non-diabetic foot ulcer: the sessing scale for assessment of pressure ulcer. Int J Basic Clin Pharmacol 2021;10:18-22. 